\title{
Regulation of Putative Muscle-derived Neurotrophic Factors by Muscle Activity and Innervation: in vivo and in vitro Studies
}

\author{
Lucien J. Houenou, ${ }^{1}$ James L. McManaman, ${ }^{2}$ David Prevette, ${ }^{1}$ and Ronald W. Oppenheim ${ }^{1}$ \\ 'Department of Neurobiology and Anatomy, and the Neuroscience Program, Bowman Gray School of Medicine, Wake Forest \\ University, Winston-Salem, North Carolina 27103 and ${ }^{2}$ Department of Neurology and Division of Neuroscience, Wagner ALS \\ Research Laboratory, Baylor College of Medicine, Houston, Texas 77030
}

The normal embryonic development of spinal cord motoneurons (MNs) involves the proliferation of precursor cells followed by the degeneration of approximately $50 \%$ of postmitotic MNs during the period when nerve-muscle connections are being established. The death of MNs in vivo can be ameliorated by activity blockade and by treatment with muscle extracts. Muscle activity and innervation have been suggested to regulate the availability of putative musclederived neurotrophic agent(s), and MNs are thought to compete for limited amounts of these trophic agents during normal development. Thus, activity and innervation are thought to regulate MN survival by modulating trophic factor availability. We have tested this notion by examining MN survival in vivo and ChAT development in spinal cord neurons in vitro following treatments with partially purified muscle extracts from normally active, paralyzed (genetically or pharmacologically), aneural, denervated, slow tonic, and fast-twitch muscles from embryonic and postnatal animals. Extracts from active and chronically inactive embryonic avian and mouse muscles were found to be equally effective in promoting the in vivo survival of MNs in the chick embryo. Similarly, extracts from fast-twitch and slow tonic postnatal avian muscles did not differ in their ability to promote both MN survival in vivo and ChAT activity in vitro. Although aneural and control embryonic muscle extracts had similar effects on ChAT development in vitro, aneural muscle extract contained somewhat less MN survival-promoting activity when tested in vivo. By contrast, denervated postnatal muscle extract was more effective in promoting both $\mathrm{MN}$ survival in vivo and ChAT activity in vitro than age-matched control muscle extract. These results suggest that (1) innervation but not muscle activity may be important for regulating the availability of putative neurotrophic agents and (2) there may be a differential regulation of neurotrophic agents during embryonic and postnatal muscle development.

\footnotetext{
Received Jan. 9, 1991; revised Apr. 16, 1991; accepted Apr. 17, 1991.

This work was supported by NIH Grants NS20402 (R.W.O.) and NS23058 (J.L.M.) and grants from the Amyotrophic Lateral Sclerosis (ALS) Society, the Muscular Dystrophy Association (MDA), and Cephalon, Inc. L.J.H. was supported by fellowships from the International Brain Research Organization (IBRO), the Beatrice Phillipe Foundation, and the MDA. We thank Dr. François Rieger for providing us with muscle samples from the mouse mutant $m d g$. We are grateful to R. Clark, R. Künzi, and L. J. Haverkamp for their help and to Joy Bauguess for manuscript preparation.

Correspondence should be addressed to Lucien J. Houenou, Ph.D., Department of Neurobiology and Anatomy, Bowman Gray School of Medicine, 300 South Hawthorne Road, Winston-Salem, NC 27103.

Copyright (C) 1991 Society for Neuroscience 0270-6474/91/112829-09\$03.00/0
}

The formation of normal connections between motoneurons (MNs) and their target muscles during embryonic development is characterized by the death of up to $60 \%$ of postmitotic MNs (reviewed by Hamburger and Oppenheim, 1982). The beginning of MN cell death coincides with the appearance of embryonic neuromuscular activity (motility) that characterizes the normal development of all vertebrate embryos (Hamburger, 1963; Oppenheim, 1982). Periods of naturally occurring $M N$ death have been described in a number of vertebrates, including chick (Hamburger, 1975; Chu-Wang and Oppenheim, 1978), rat (Harris and McCaig, 1984; Oppenheim, 1986), mouse (Lance-Jones, 1982; Oppenheim et al, 1986), and human (Forger and Breedlove, 1987) embryos.

Previous studies have shown that chronic paralysis of chick (Laing and Prestige, 1978; Pittman and Oppenheim, 1978, 1979; Oppenheim, 1984), mouse (Houenou et al., 1990b), and rat (Harris and McCaig, 1984) embryos with neurotoxins during the naturally occurring cell death period results in a substantial increase in surviving MNs. It is generally thought that MNs compete for target-derived agent(s) that exist in subsaturating amounts relative to the total number of MNs present prior to cell death. The increased survival of MNs following the blockade of neuromuscular activity has been suggested to result from increased production or availability of target-derived trophic agents (Pittman and Oppenheim, 1978, 1979; Hamburger and Oppenheim, 1982; Oppenheim, 1987, 1989).

A number of studies have demonstrated that crude or partially purified skeletal muscle extracts as well as purified muscle proteins can influence the survival, growth, and differentiation of spinal cord neurons both in vitro (Henderson et al., 1981; Hsu et al., 1982; Calof and Reichardt, 1984; Dohrmann et al., 1986, 1987; O'Brien and Fischbach, 1986; McManaman et al., 1988; Martinou et al., 1989) and in vivo (Oppenheim et al., 1988; McManaman et al., 1990). However, the extent to which neuromuscular activity and muscle innervation regulate the production of putative neurotrophic factor(s) by developing skeletal muscle is still poorly understood. A recent study by Tanaka (1987) has shown that the paralysis of chick embryos with curare during the period of naturally occurring $\mathrm{MN}$ death does not alter the level of neurotrophic (survival-promoting) activity in skeletal muscle extracts when tested on MNs in vitro. In contrast, denervation has been reported to enhance neurotrophic activities in skeletal muscle (Henderson et al., 1983; Hill and Bennett, 1986).

To determine whether either neuromuscular activity or muscle innervation alters neurotrophic activity(ies) in skeletal mus- 
cle, we examined ChAT development in rat spinal cord neurons in vitro and chick $\mathrm{MN}$ survival in vivo following treatment with partially purified extracts from control, inactive, aneural, denervated, slow tonic (multiply innervated), and fast-twitch (singly innervated) muscles from embryonic and postnatal chickens and mice. Our results show that inactive and aneural embryonic muscle extracts do not increase MN survival over that obtained by control embryonic muscle, whereas denervated postnatal muscle extract is more effective in promoting both $\mathrm{MN}$ survival in vivo and ChAT development in vitro.

These results have been presented previously in abstract form (Houenou et al., 1989, 1990a).

\section{Materials and Methods}

\section{Animals and experimental procedures}

Chick and mouse embryos. Fertilized eggs from normal White Leghorn chickens (Hubbard Farm, Statesville, NC) and from heterozygous animals carrying the gene crooked neck dwarf ( $\mathrm{cn}$; Department of Animal Genetics, University of Connecticut, Storrs, CT) were incubated in a forced-draft rotating incubator at $37^{\circ} \mathrm{C}$ and $60 \%$ relative humidity. On embryonic day 4 (E4), eggs were candled, and a window approximately $1 \mathrm{~cm}$ in diameter was made in the shell. The window was sealed with a piece of tape, and eggs were returned to the incubator. Homozygous mutants $(\mathrm{cn} / \mathrm{cn})$ may be recognized as early as $\mathrm{E} 4$ by the total absence of neuromuscular activity (motility) and, at more advanced stages (i.e., $>$ E9), by an edematous epidermis in the abdominal region and by a short ("crooked") neck and muscular atrophy (Asmundson, 1945; Rosemberg, 1947; Wich and Allenspach, 1978; Oppenheim and Prevette, 1986). Control and mutant embryos were killed on E10, and their hindlimb muscles were dissected and quickly frozen at $-80^{\circ} \mathrm{C}$.

E18 limb muscles were also dissected from control mice and the mouse mutant muscular dysgenesis ( $m d g$ ), in which neuromuscular activity is absent during gestation (Gluecksohn-Waelsch, 1963; Pai, 1965).

To obtain pharmacologically inactive embryonic muscles, normal chick embryos were injected daily from E5 to E9 with $1.5 \mathrm{mg}$ of $d$ tubocurarine (dTC; Sigma, St. Louis, MO) through a small window in the shell as described previously (Pittman and Oppenheim, 1979). Control embryos were treated with saline solution. Hindlimb muscles were dissected from both E10 control and curare-treated embryos and kept frozen at $-80^{\circ} \mathrm{C}$.

To create aneural embryonic chick muscles, the lumbar neural tube between somites 23 and 30 was removed on E2 (i.e., prior to hindlimb muscle innervation; Landmesser, 1978; Bennett et al., 1983) as described previously (Fig. 1; Hamburger, 1966). Operated embryos were allowed to develop until E10, at which stage they were killed and limb muscles were dissected as described above. Before death, operated embryos were monitored for spontaneous (neurogenic) hindlimb motility (Pittman and Oppenheim, 1979), and only those with no apparent hindlimb motility were retained for this experiment. Embryos were also carefully dissected to confirm the total absence of the lumbar spinal cord.

Postnatal chickens. Lower leg muscle denervation was performed on postnatal day 6 (PN6) in White Leghorn chickens (Hubbard Farm, Statesville, NC) by sciatic nerve section at the mid-thigh level following anesthesia with sodium pentobarbital $(16 \mu \mathrm{g}$ in $0.2 \mathrm{ml}$ of $0.9 \% \mathrm{NaCl}$, $\mathrm{pH}$ 7.4) administered by subcutaneous injection. A $5 \mathrm{~mm}$-long piece of sciatic nerve was removed to avoid muscle reinnervation. Thirteen operated hatchlings were used for this experiment. On PN10, operated animals (100\% survival) were examined for the presence of a complete paralysis of the denervated leg and killed by chloroform overdose. Both denervated and contralateral lower leg muscles were dissected free of nonmuscle tissues and frozen at $-80^{\circ} \mathrm{C}$. Muscles from six nonoperated chickens (PN10) were also used as normal controls.

In another series of experiments, anterior and posterior latissimus dorsi (ALD and PLD, respectively) muscles were dissected from 10 hatchlings on PN 10 and kept frozen at $-80^{\circ} \mathrm{C}$ until used for preparing muscle extracts.

\section{Preparation and partial purification of muscle extracts}

Muscle extracts were prepared from E10 control, mutant ( $c n)$, dTCtreated, and aneural embryonic chick hindlimb muscles; E18 control and mutant ( $m d g$ ) embryonic mouse muscles; and PN10 control, contralateral, and denervated leg muscles and control ALD and PLD muscles.

Samples were thawed on ice and homogenized using a Polytron apparatus at setting 4 for $2 \times 30 \mathrm{sec}$, in $2-3$ vol of phosphate-buffered saline (PBS; $137 \mathrm{~mm} \mathrm{NaCl}, 2.7 \mathrm{mM} \mathrm{KCl}, 8.1 \mathrm{~mm} \mathrm{Na} \mathrm{HPO}_{4}, 1.5 \mathrm{~mm}$ $\mathrm{KH}_{2} \mathrm{PO}_{4}$, pH 7.4) containing $1 \mathrm{~mm}$ EDTA, $1 \mathrm{~mm}$ EGTA, $1 \mathrm{~mm}$ benzamidine, $1 \mathrm{~mm} N$-ethylmaleimide, and $0.1 \mathrm{~mm}$ phenylmethylsulfonyl fluoride. Homogenates were centrifuged at 23,000 $\times \mathrm{g}$ for $1 \mathrm{hr}$ (Sorvall $\mathrm{RC2}$, rotor SS-34), and the resulting supernatant, referred to as crude muscle extract, was either dialyzed or applied to further purification steps. Using a saturated solution of ammonium sulfate $\left(\mathrm{AmSO}_{4}\right)$ at $4^{\circ} \mathrm{C}$, the crude extract was separated into three fractions designated $F_{1}, F_{2}$, and $\mathrm{F}_{3}$, corresponding to $0-25 \%, 25-75 \%$, and $75-100 \% \mathrm{AmSO}_{4}$, respectively. After centrifugation $(15,000 \times \mathrm{g}$ for $30 \mathrm{~min})$, the pellets were resuspended in PBS, dialyzed for $36-48 \mathrm{hr}$ (Spectra/Por membrane; MWCO, $1000 \mathrm{kDa}$ ), and stored in $1-2-\mathrm{ml}$ aliquots at $-80^{\circ} \mathrm{C}$. Protein concentrations were determined as described by Lowry et al. (1951).

\section{Biological assays of muscle extracts}

Because most of the MN survival-promoting (neurotrophic) activity has been shown to be associated with the 25-75\% $\mathrm{AmSO}_{4}$ fraction (Dohrmann et al., 1986; Oppenheim et al., 1988), only this fraction has been tested in the present study, except for one group (denervated postnatal muscle) in which crude extracts were also tested. Samples were tested for their ability both to enhance ChAT development in tat spinal cord neurons in vitro (McManaman et al., 1988) and to promote embryonic chick MN survival in vivo (Oppenheim et al., 1988).

\section{In vitro assay}

Dissociated primary cultures were prepared from the ventral spinal cords of E14 rats, as described previously (McManaman et al., 1985). Briefly, dissociated cells were plated at a density of $500,000 /$ well in poly-L-lysine coated $16 \mathrm{~mm}$-diameter multiwell dishes (Falcon). The cultures were maintained in Dulbecco's modified Eagle's medium, supplemented with $10 \%$ heat-inactivated horse serum, $0.4 \%$ glucose, $2 \mathrm{~mm}$ glutamine, and $0.08 \%$ gentamicin, in a humidified atmosphere of $10 \%$ $\mathrm{CO}_{2}$ and $90 \%$ air at $37^{\circ} \mathrm{C}$. One hour after plating, cultures were treated with $1-30 \mu \mathrm{l}$ of either muscle extract or PBS (pH 7.4). Two days later, the medium was removed, and after solubilization, ChAT activity was measured using the method of Ishida and Deguchi (1983).

\section{In vivo assay}

Eggs were incubated under standard conditions, and a small window was made in the shell overlying the vascularized chorioallantoic membrane (CAM) on E5. Two hundred microliters of either partially purified muscle extracts or $0.9 \%$ saline were applied daily to the CAM from E6 to E8. On E9, embryos were staged according to Hamburger and Hamilton (1951), and the lumbar spinal cords were dissected out and processed for paraffin embedding. MN counts in the lateral motor column (LMC) were carried out blind on $8 \mu \mathrm{m}$ serial sections using criteria described previously (Chu-Wang and Oppenheim, 1978; Oppenheim et al., 1989).

Before death, all muscle extract-treated embryos were monitored on E9 for limb movements in order to determine whether neuromuscular activity (motility) was altered by the treatment paradigm (Pittman and Oppenheim, 1979).

\section{Results}

Effects of chronic paralysis on MN survival and the level of neurotrophic activities in embryonic muscle

E10 $\mathrm{cn}$ and curare-treated $\left(\mathrm{dTC}^{+}\right)$chick embryos exhibited a significant increase $\left(c n, 40 \%\right.$; $\left.\mathrm{dTC}^{+}, 64 \%\right)$ in $\mathrm{MN}$ number when compared to age-matched controls (Fig. 2). Similarly, dysgenic mouse $(m d g)$ embryos also exhibit increased (100\%) MN numbers versus controls on E18 (Oppenheim et al., 1986). The increased MN number in dTC-treated chick embryos is similar to that reported previously for embryos exposed to the same regimen of activity blockade (Laing and Prestige, 1978; Pittman and Oppenheim, 1978, 1979). 


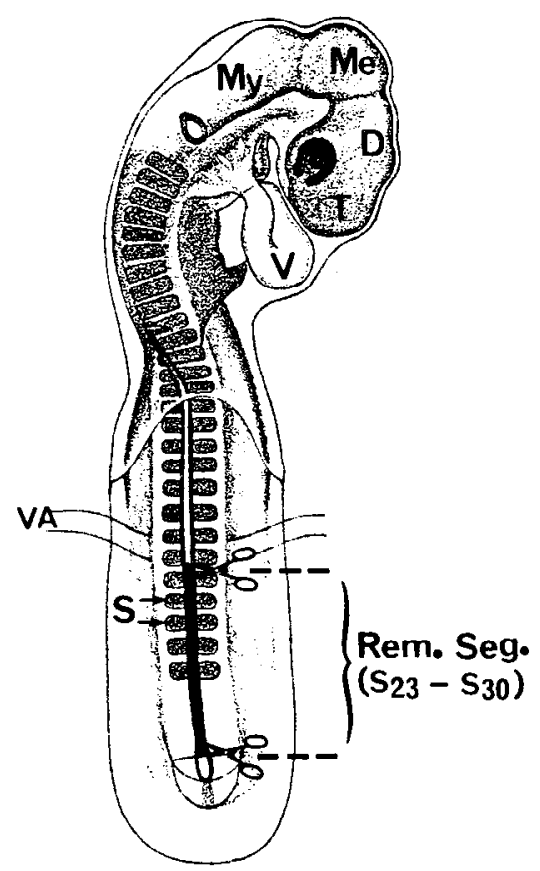

Figure 1. Schematic representation of experimental removal of the lumbar neural tube from an E2 chick embryo to create aneural hindlimb muscles. The removed segments (solid black) extend from somite $(S)$ $23\left(S_{23}\right)$ to $S_{30}$. D, diencephalon; $M e$, mesencephalon; $M y$, myelencephalon; $T$, telencephalon; $V$, heart; $V A$, vitelline artery.

This enhanced MN survival may have been due to increased neurotrophic activities exhibited by the chronically paralyzed muscles. We therefore examined the effects of partially purified muscle extracts from active and inactive embryos, including muscles obtained from the same embryos used for MN counts. Devcloping chick cmbryos werc treatcd daily from E6 to E8 with partially purified extracts and examined on E9 for MN survival. As shown in Figure 3, all muscle extracts tested enhanced MN survival in vivo in a dose-dependent manner. However, there were no significant differences between inactive embryonic chick muscle extracts (dTC.CMX and cn.CMX) and normally active muscle extracts (nor.CMX) at any dose tested (Fig. 3). Similarly, genetically inactive ( $m d g$ ) embryonic mouse muscle extracts (mdg.MMX) did not exhibit more MN survivalpromoting activity than control extracts (Fig. 4). Furthermore, assessment of the dose-response effects of muscle extracts on ChAT development in rat spinal cord cultures also indicated that there was no increased neurotrophic activity in dTC.CMX versus control (data not shown), in agreement with a previous report by Tanaka (1987).

\section{Levels of neurotrophic activities in noninnervated embryonic muscle}

To examine whether innervation alters the level of musclederived neurotrophic agents during embryonic development, we have created aneural embryonic muscles by removing the lumbar spinal cord on E2 as shown in Figure 1. Out of 157 operated embryos, 31 survived the operation and exhibited no spontaneous hindlimb motility on E10, and following dissection, the lumbar spinal cord was found to be totally absent. "Aneural embryos" did not exhibit any gross morphological differences compared to E10 control embryos. No significant differences

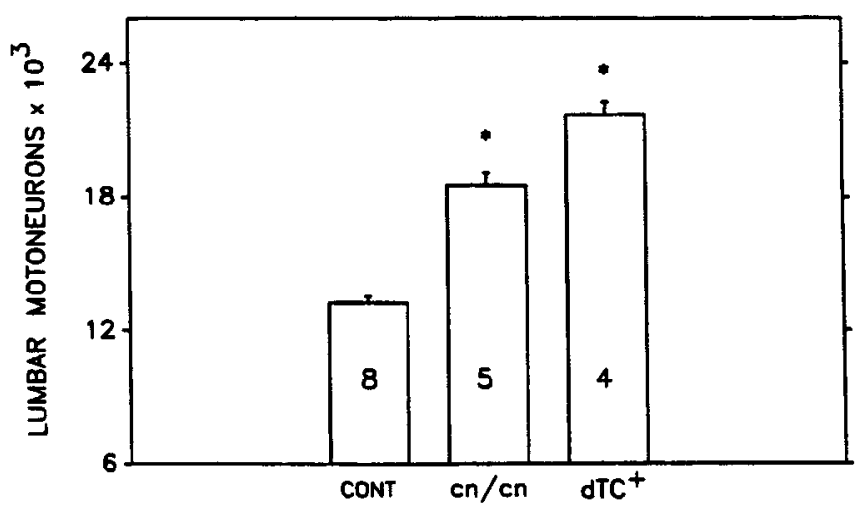

Figure 2. MN numbers (means \pm SEM) in the lumbar spinal cord of control $(C O N T)$ and genetically $(\mathrm{cn} / \mathrm{cn})$ and pharmacologically $\left(d T \mathrm{C}^{+}\right)$ inactive chick embryos on E10. Sample sizes are indicated by numbers in bars. ${ }^{*}, p<0.0001$ versus CONTROL, $t$ test.

were observed between aneural muscle extract (aneur.CMX) versus nor.CMX in their ability to enhance ChAT activity in spinal cord cultures (Fig. 5A). However, aneur.CMX was somewhat less effective than nor.CMX in promoting embryonic $\mathrm{MN}$ survival in vivo (Fig. 5B).

Quantitative assessment of neurotrophic activities in singly and multiply innervated muscles

If the amount of neurotrophic factor(s) in a muscle is critical in determining the number of MNs that survive and innervate that muscle, then ALD, whose myofibers are multiply innervated (e.g., Bourgeois and Toutant, 1982), might be expected to have higher levels of neurotrophic activity than PLD, which is composed primarily of singly innervated fibers (Bourgeois and Toutant, 1982). To examine this possibility, we have tested the effects of partially purified extracts from both ALD and PLD muscles on ChAT activity in vitro and on MN survival in vivo.

As shown in Figure 6, extracts from both ALD and PLD muscles promote ChAT development in spinal cord cultures

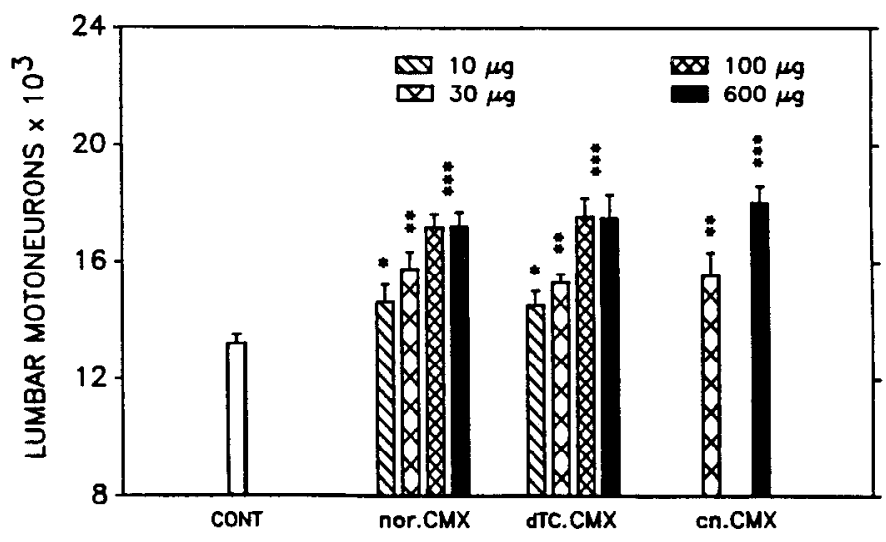

Figure 3. MN numbers (means \pm SEM) in the lumbar spinal cords of E9 chick embryos treated daily with saline (CONT), normally active (nor. $C M X)$, curare-treated (dTC.CMX), or mutant $c n / c n(c n . C M X) \mathrm{em}$ bryonic muscle extracts. Equal volumes $(0.2 \mathrm{ml})$ of muscle extracts with protein concentrations ranging from 10 to $600 \mu \mathrm{g}$ were administered daily from E6 to E8. Each value represents the mean of four to eight embryos. Significance ( $t$ test): ${ }^{*}, p<0.04$ versus control; ${ }^{* *}, p<0.001$ versus control and $p<0.05$ versus $10 \mu g ; * * *, p<0.0001$ versus control and $p<0.02$ versus $30 \mu g$. There were no significant differences between nor.CMX, dTC.CMX, and cn.CMX at any of the doses tested $(p>0.3)$. 


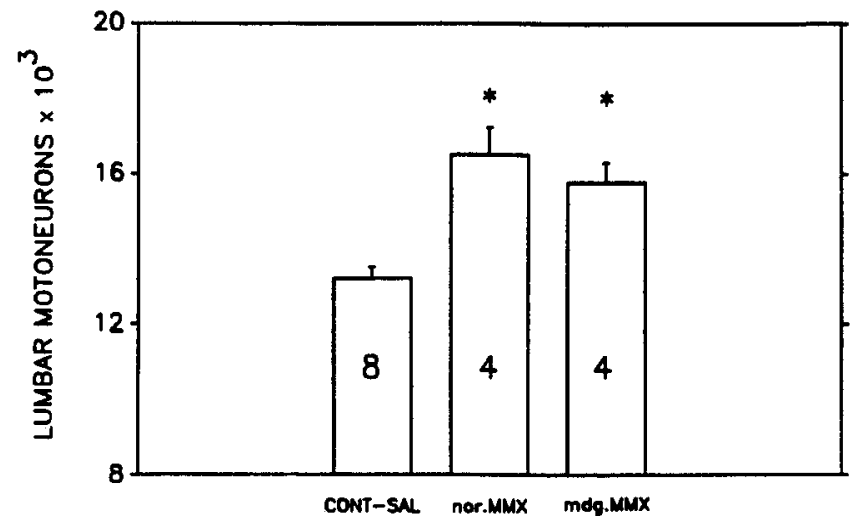

Figure 4. MN numbers (means \pm SEM) in the lumbar spinal cord of E9 chick embryos treated daily with saline (CONT-SAL), or normally active (nor.MMX) or mutant $m d g$ ( $m d g . M M X$ ) embryonic muscle extracts. Only one dose ( $600 \mu \mathrm{g}$ protein daily) was tested. Numbers in bars are sample sizes. ${ }^{*}, p<0.001$ versus control, $t$ test.
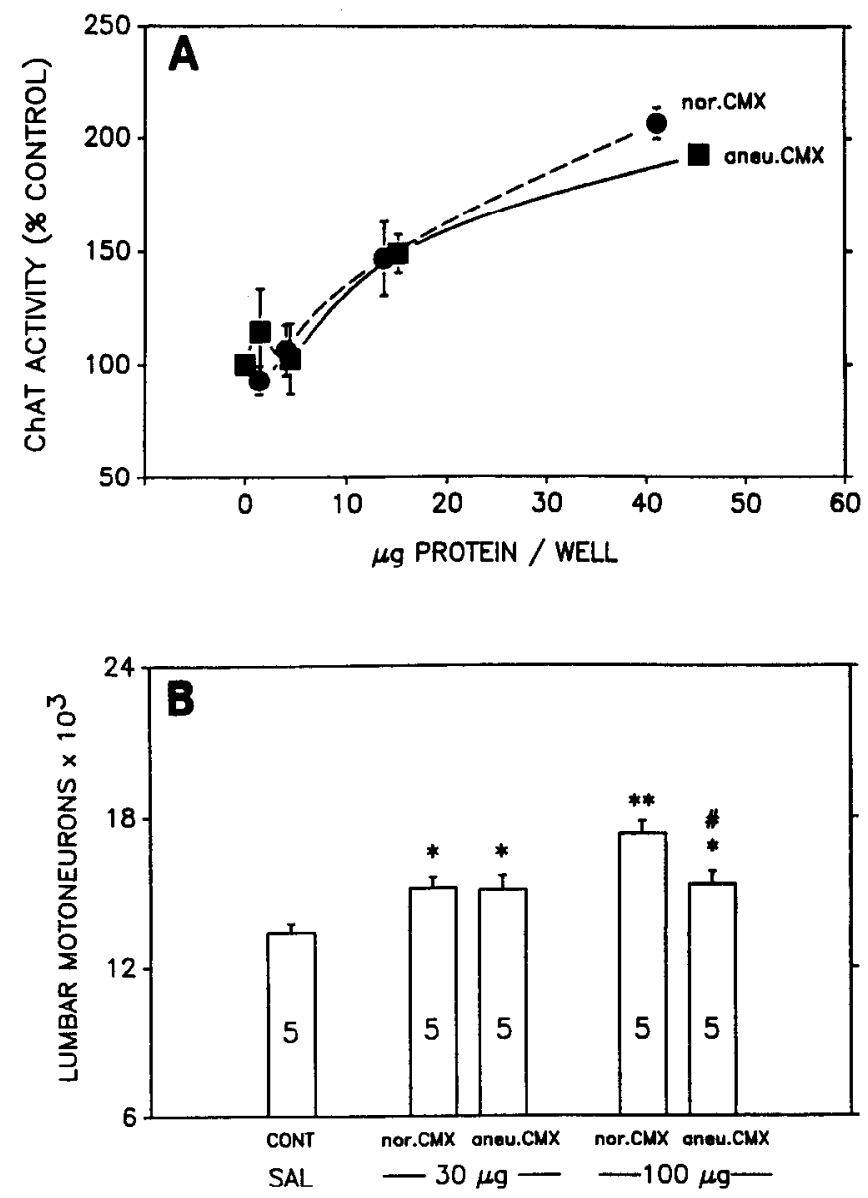

Figure 5. Neurotrophic activities of partially purified extracts from normally active (nor.CMX) and aneural (aneu.CMX) embryonic chick muscles on ChAT development in E14 rat spinal cord cultures $(A)$ and chick MN survival in vivo on $\mathrm{E} 9(B) . A$, each point represents the mean $\pm \mathrm{SD}$ of three determinations. For MN survival $(B)$, results are the means \pm SEM (sample sizes are given by numbers in the bars). CONT $S A L$, saline-treated control. Significance ( $t$ test): *, $p<0.03$ versus control; ${ }^{* *}, p<0.001$ versus control and $p<0.02$ versus nor. $C M X 30$ $\mu g ; \#, p<0.03$ versus nor. CMX $100 \mu g$.
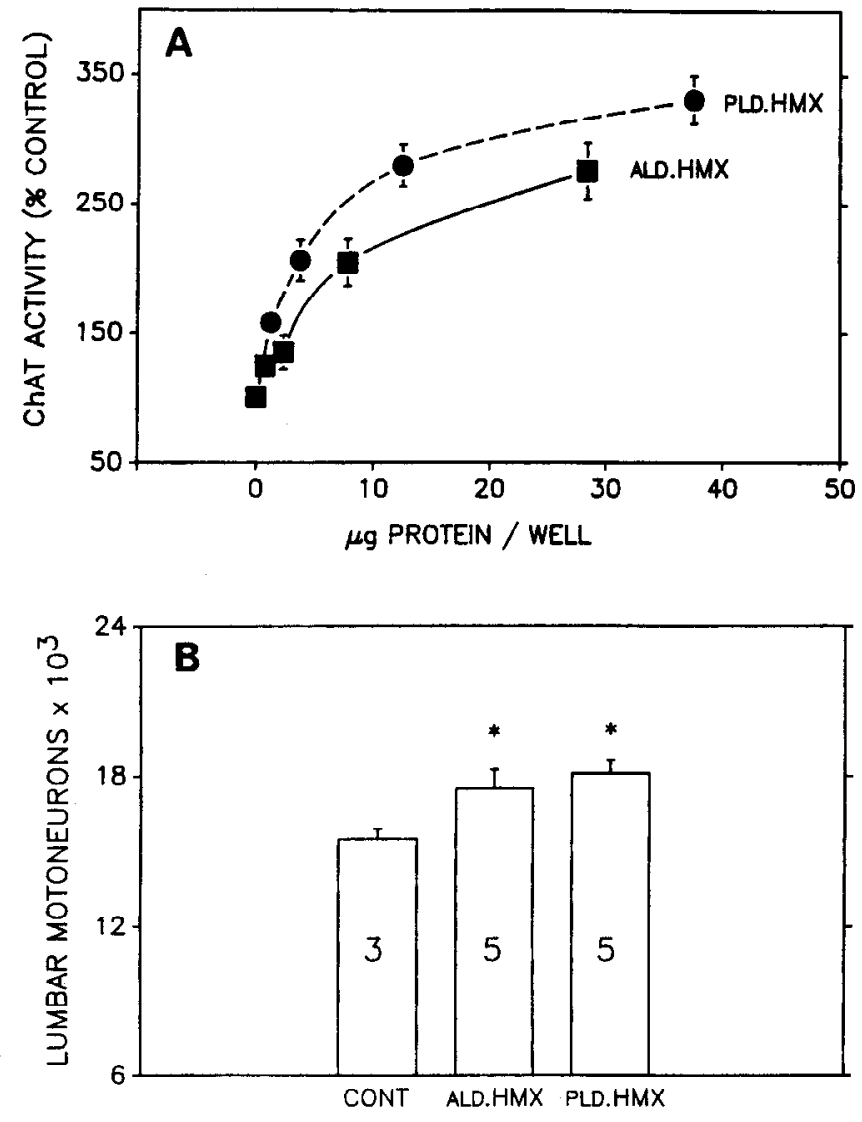

Figure 6. Neurotrophic activities of partially purified extracts from anterior $(A L D . H M X)$ and posterior (PLD.HMX) latissimus dorsi muscles of hatchlings on ChAT development in E14 spinal cord cultures $(A)$ and chick MN survival in vivo on E8 $(B)$. For ChAT activity $(A)$, each point is the mean \pm SD of three determinations. For MN survival $(B)$, results are from one dose ( $30 \mu$ g protein daily) and are expressed as the mean \pm SEM (sample sizes are given by numbers in the bars). $*, p<0.02$ versus control, $t$ test.

and $\mathrm{MN}$ survival in vivo. However, there were no apparent differences in the abilities of ALD and PLD to promote ChAT activity (Fig. 6A) and MN survival (Fig. 6B).

\section{Effects of denervation on neurotrophic activities in postnatal muscle}

In an attempt to determine whether denervated postnatal muscle extracts can enhance either neuronal cholinergic (ChAT) differentiation in vitro or embryonic MN survival in vivo, in addition to their demonstrated ability to increase neurite outgrowth (Henderson et al., 1983), denervated, contralateral, and normal hatchling muscle extracts (den.HMX, clt.HMX, and nor.HMX, respectively) were prepared. Both crude and partially purified fractions of these extracts were tested for neurotrophic activities as described above.

All crude muscle extracts exhibited an apparent toxic or inhibitory effect on ChAT development in vitro (Fig. 7). However, den.HMX produced less of this putative toxic effect than either clt.HMX or nor.HMX (Fig. 7). Further purification steps, when applied to the crude extracts, eliminated these toxic effects, and, in fact, as shown in Figure $8 A$, the partially purified den.HMX exhibited more ChAT-promoting activity in spinal cord cultures than either of the control extracts (clt.HMX and nor.HMX).

As clt.HMX did not differ from nor.HMX in promoting ChAT 


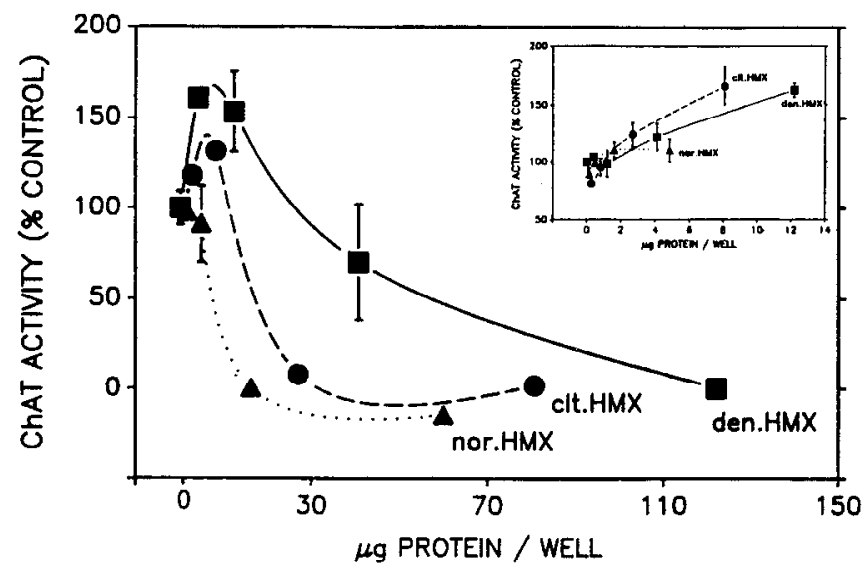

Figure 7. Development of ChAT activity in E14 rat spinal cord cultures following treatment with crude extracts from normally aclive (nor. $H M X)$, contralateral (clt.HMX), and denervated (den.HMX) hatchling muscles. Positive effects are only observed at very low protein concentrations (see inset). Each point is the mean $\pm \mathrm{SD}$ of three determinations.

activity in vitro (Fig. $8 A$ ), only clt.HMX has been subsequently used as a control for in vivo studies of MN survival. Both clt.HMX and den.HMX enhanced MN survival in ovo when compared to saline (Fig. $8 B$ ). However, MN survival-promoting activity was significantly higher $(12-15 \% ; p<0.03)$ in den.HMX versus clt.HMX at two (i.e., 30 and $100 \mu \mathrm{g}$ protein) of the three doses tested (Fig. $8 B$ ). At the lowest dose tested (10 $\mu$ g protein), both clt.HMX and den.HMX were ineffective $(p>0.2)$.

\section{Neuromuscular activity (motility) in muscle extract-treated embryos}

Daily injections of chick embryos with either embryonic or postnatal skeletal muscle extracts did not alter neuromuscular activity (Fig. 9). Thus, the increased MN survival observed in muscle extract-treated embryos cannot be accounted for by reduced motility (e.g., Pittman and Oppenheim, 1978).

\section{Discussion}

The two major goals of these experiments were (1) to determine whether either muscle contractile activity or innervation plays a role in the regulation of the levels of muscle-derived neurotrophic agent(s) and (2) to examine the possibility that neurotrophic agent(s) may be differently regulated in embryonic versus postnatal muscle. Partially purified extracts of functionally impaired or denervated muscles derived from embryonic and postnatal chickens were tested using two different bioassay systems: neuronal ChAT development in vitro and developing $\mathrm{MN}$ survival in vivo. The use of an in vivo assay to test the ability of muscle extracts to promote MN survival is necessary, in that putative neurotrophic factors might affect a population of neurons in vitro by mechanisms that are never operative in vivo. The demonstration that exogenous sources of putative neurotrophic agents (e.g., muscle extracts) can rescue MNs that would otherwise die indicates that such agents are very likely mimicking the effects of endogenous neurotrophic molecules whose availability is somehow limited during normal development. However, at present, we do not know whether these agents also promote ChAT development in vivo. Muscle extracts were able to rescue MNs in vivo without altering neuromuscular activity.
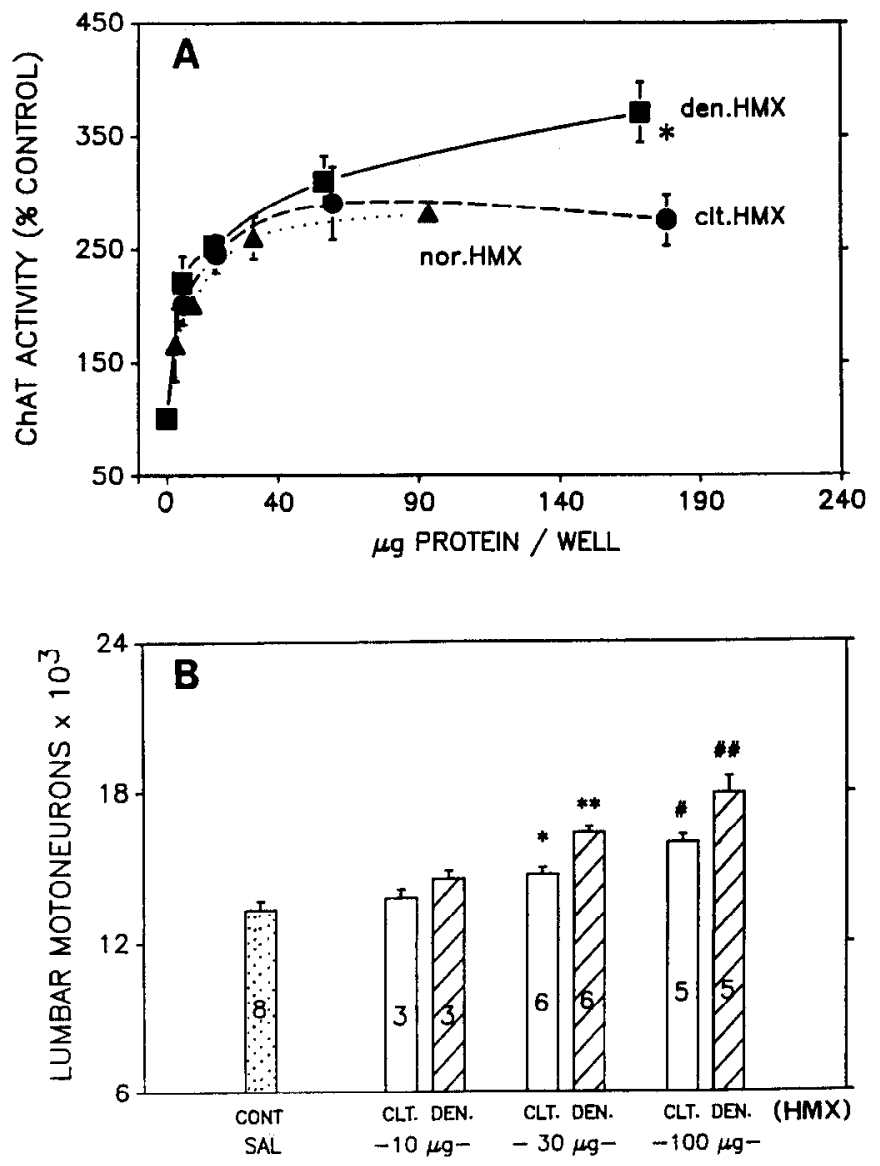

Figure 8. Neurotrophic activities of partially purified extracts from normally active (nor.HMX), contralateral (clt.HMX), and denervated (den.HMX) hatchling muscles on ChAT development in E14 rat spinal cord cultures $(A)$ and chick MN survival in vivo on E9 $(B)$. Each point represents the mean $\pm \mathrm{SD}$ of three determinations in $A$ and the mean \pm SEM (sample sizes are given by numbers in the bars) in $B$. Significance ( $t$ test): ${ }^{*}, p<0.02$ versus clt.HMX (or versus control); ${ }^{* *}, p<0.002$ versus $C L T 30 \mu g$; \#, $p<0.02$ versus $C L T 30 \mu g$; \#\#, $p<0.03$ versus $C L T 100 \mu g .10 .30$, and $100 \mu g$ refer to the amounts of muscle protein administered daily. Extracts used here are the $25-75 \% \mathrm{AmSO}_{4}$ fractions of the crude cxtracts tested in Figure 7.

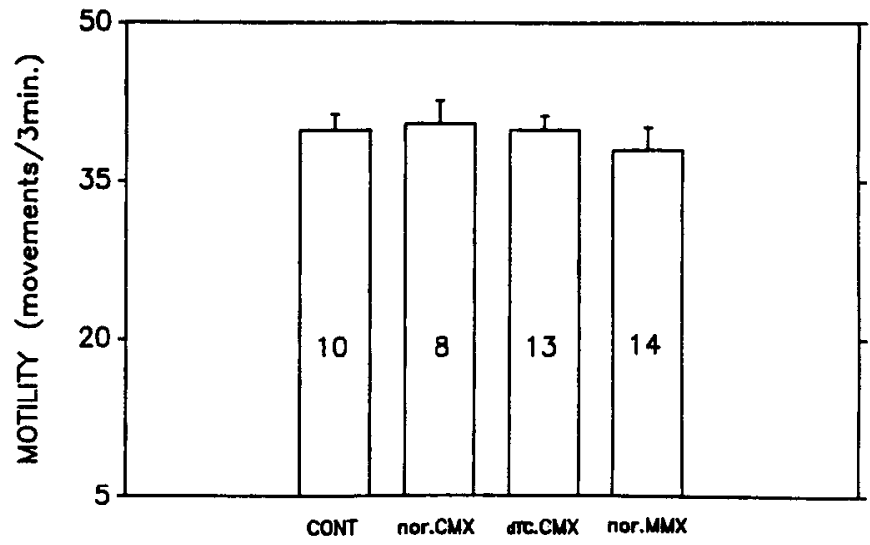

Figure 9. Chick hindlimb motility (mean movements \pm SEM) on E9 following treatment with saline (CONT) and with normal and curaretreated chick (nor. $C M X$ and $d T C . C M X$, respectively) and normal mouse (nor. $M M X$ ) embryonic muscle extracts. Numbers in the bars are sample sizes. 
Accordingly, we conclude that muscle extracts promote survival by a direct action on $\mathrm{MN}$ death rather than by acting indirectly via activity blockade. Although we cannot entirely exclude an indirect in vivo action of muscle extracts on MNs through the release of factors from other spinal cord cells (e.g., interneurons or glia), in vitro studies indicate that putative trophic agents derived from muscle can promote survival by acting directly on MNs (Calof and Reichardt, 1984; Dohrmann et al., 1986; O'Brien and Fischbach, 1986; Tanaka, 1987; Arakawa et al., 1990; BlochGallego et al., 1991).

We have shown that chronically paralyzed embryonic muscles appear to contain normal levels, whereas aneural embryonic muscles contain decreased amounts of putative neurotrophic factor(s), when compared to controls. By contrast, denervated postnatal muscles exhibit greater neurotrophic activities (ChAT development and MN survival) than age-matched control muscles.

\section{Activity, putative neurotrophic factors, and embryonic $M N$ survival}

The present results, indicating that chronically inactive embryonic muscle does not contain increased $\mathrm{MN}$ survival-promoting activity, are not consistent with earlier suggestions that activity regulates the synthesis or production of a muscle-derived MN trophic agent (Pittman and Oppenheim, 1979; Oppenheim, 1987). However, these data support the conclusions of Tanaka (1987), who reported that muscle extracts derived from chronically paralyzed chick embryos were no more effective in promoting MN survival in vitro than were extracts from normally active muscles (but see Hsu et al., 1984). Furthermore, we have also found that neurotrophic activities in singly and multiply innervated muscles (i.e., PLD and ALD) that exhibit different patterns and amounts of both innervation and physiological activity (Atsumi, 1977; Gordon et al., 1977; Srihari and Vrbova, 1978; Barnard et al., 1982; Bourgeois and Toutant, 1982) do not differ. The failure to find a difference between the ALD and PLD in this situation suggests that (1) the numbers of motor axons (and MNs) innervating a muscle may not be strictly regulated by levels of ncurotrophic factors and (2) differences in physiological activity between fast and slow muscles may not regulate the levels of trophic agents produced. However, because this experiment used as starting material muscles from posthatching chicks, it is possible that the ALD and PLD differ in survival-promoting activity at embryonic stages when innervation and cell death are occurring.

When considered collectively, these data indicate that the survival of only one-half of all postmitotic MNs during normal development may not reflect a competition for limited amounts of muscle-derived trophic agents. Instead, these data would indicate that trophic factor availability may be limited by some other means. One possibility discussed previously is that trophic factor availability may be limited by access to trophic agents that are produced in sufficient amounts to support all postmitotic MNs (Oppenheim, 1989). The regulating factor, according to this view, is access to sufficient trophic agent through the number, or efficacy, of neuromuscular contacts. Activity would regulate $\mathrm{MN}$ survival by modulating the amount of axonal branching and the number of synaptic contacts or growth cones, perhaps via the modulation of molecular sprouting or synaptogenic signals (Oppenheim and Chu-Wang, 1983; Dahm and
Landmesser, 1988; Landmesser et al., 1988, 1990) rather than by regulating synthesis or production of trophic agents. During normal development, MNs may differ in their capacity to branch, to establish contacts, and to gain access to trophic agents, and in this way the cells would differ in their potential for survival. The acuss hypothesis is supported by the recent demonstration that in vivo treatment of chick embryos with an endosialidase results in a significant decrease in both nerve branching and motoneuron survival without affecting neuromuscular activity (L. Landmesser, unpublished data). However, because neuromuscular blocking agents such as curare have also been shown to alter MN activity directly (Landmesser and Szente, 1987), these agents may rescue MNs by some means independent of muscle activity. For instance, inactive MNs may require lower amounts of a muscle-derived trophic agent for their survival. This would be consistent with our present observations as well as those of Tanaka (1987) indicating that trophic agents are not upregulated in paralyzed muscles. Against this possibility is the observation that $\mathrm{MN}$ activity appears normal in the $m d g$ mouse (Bournaud, 1980; Rieger et al., 1980) and $c n$ avian (R. W. Oppenheim and L. Landmesser, unpublished observations) mutants, yet cell death is reduced in these animals similar to normal embryos treated with neuromuscular blocking agents. Furthermore, deafferentation or blockade of afferent synaptic input results in increased, not decreased, cell death in several developing systems (Wright 1981; Okado and Oppenheim, 1984; Furber et al., 1987; Born and Rubel, 1988; Maderdrut et al., 1988; Pasic and Rubel, 1989).

The ability of a single limb in the amphibian Xenopus laevis to support twice the normal number of MNs is also consistent with the possibility that trophic factor availability is not inherently limited by synthesis or production (Lamb, 1980; Denton et al., 1985; Lamb et al., 1988). In this case, either sufficient trophic agent is normally present to support many more neurons than would typically innervate a single limb, or the excess innervation (created experimentally) induces or upregulates trophic factor production to accommodate the increased number of MNs that must be maintained. Neither possibility is consistent with the currently most popular version of the neurotrophic hypothesis (Barde, 1988; Davies, 1988). By contrast, following similar experimental increases in target innervation in both the spinal sensory and visual system, the results are more in line with the idea that trophic factor availability is limited by inherent constraints on its synthesis (O'Leary and Cowan, 1984; Lamb et al., 1988). Direct measurements of NGF mRNA in peripheral targets of sensory neurons during development also indicate that inherent differences in NGF production by targets are likely to be primarily responsible for regulating the number of sensory neurons that can be supported by specific target regions (Harper and Davies, 1990). Taken collectively, these results suggest that trophic factor availability may be regulated differently in different neuronal populations. Although the present data suggest that MN survival may not be regulated by the limited production of trophic agents by targets, neither the present results nor the studies by Lamb (1980) and Lamb et al. (1988) are conclusive on this issue. Only direct measurements of purified proteins and/or their mRNAs in normal, activityblocked, and hyperinnervated muscles will allow a decision between the two hypotheses. This will require the purification of the relevant trophic agents and the development of appropriate assays and probes. 
Regulation of putative neurotrophic factor production by embryonic muscle innervation

The decreased MN survival-promoting activity in aneural embryonic muscle suggests that innervation may play a role in the modulation of muscle-derived trophic factor(s). Although it is well established that muscle development at some stages depends critically on the presence and function of innervating MNs (e.g., Harris, 1981; Ross et al., 1987a,b), aneural embryonic chick limb muscle has been previously reported to develop normally up to E10 (Butler et al., 1982; Phillips and Bennett, 1984), which is the age at which muscles were used for preparing muscle extracts in the present study. However, a more recent study indicates that at least some aneural muscles have fewer myotubes by E10 (Fredette and Landmesser, 1991). Accordingly, it is possible that the modest decrease in trophic factor activity in aneural muscle used by us is because of alterations in myogenesis. In addition, the absence of nerves and Schwann cells in the aneural muscle may also contribute to the apparent downregulation of trophic activity. Because the aneural condition has only a modest effect on MN survival in vivo, however, it seems likely that neither altered myogenesis nor the absence of nerve and Schwann cells is a major factor in the regulation of trophic activity in this situation. Furthermore, chronic activity blockade also alters myogenesis before E10 (Oppenheim and Chu-Wang, 1983; Fredette and Landmesser, 1991), but, as we have shown here, muscle extracts from these embryos are indistinguishable from control extracts in their ability to promote MN survival. In related experiments, it was reported that levels of NGF mRNA are identical in innervated and aneural chick hindlimbs (Rohrer et al., 1988).

\section{Regulation by motility of putative neurotrophic factor production in postnatal muscle}

In contrast to the effect of the absence of innervation (aneural) on trophic factor activity in embryonic muscle (i.e., no change or downregulation), denervation results in an apparent upregulation of both ChAT-stimulating and MN survival-promoting activities in postnatal muscle. These data confirm and extend previous reports showing that postnatal denervation results in an upregulation of neurite-promoting and $\mathrm{MN}$ survival-promoting activities in muscles when tested in vitro (Henderson et al., 1983; Hill and Bennett, 1983, 1986; Nurcombe et al., 1984). However, until it is possible to measure the synthesis of specific muscle-derived trophic agents directly, it is not possible to conclude that these effects reflect increased production by targets. One alternative explanation of these postnatal data (in vitro and in vivo) is that this apparent increase reflects a buildup of trophic agents owing to an absence of uptake by nerve endings rather than to an increased synthesis. However, it has been shown that tetrodotoxin-paralyzed (Pestronk and Drachman, 1978) and tenotomized (Henderson et al., 1986) adult rat muscles in which innervation is intact also have increased activity for nerve sprouting and neurite outgrowth. The results from our own aneural experiment also indicate that the lack of nerve terminals for uptake does not result in a buildup of trophic agent. Accordingly, it seems more likely that the increase in ChAT-stimulating and $\mathrm{MN}$ survival-promoting activities in denervated postnatal muscle may reflect a direct effect on gene expression or on the metabolic pathways for trophic agent synthesis. In this respect, denervation appears to have different effects on embryonic versus postnatal muscles. Aneural embryonic muscle appears to contain somewhat less and denervated postnatal muscle contains more survival-promoting activity when tested on MNs in vivo. Thus, the availability of putative muscle-derived neurotrophic agents may be regulated differently during embryonic and postnatal development in the chick. Alternatively, the fact that aneural muscle has never been contacted by axons, whereas postnatal denervated muscle is initially innervated, may result in entirely different responses by muscle in the two situations.

\section{References}

Arakawa Y, Sendtner M, Thoenen H (1990) Survival effect of ciliary neurotrophic factor (CNTF) on chick embryonic motoneurons in culture: comparison with other neurotrophic factors and cytokines. J Neurosci 10:3507-3515.

Asmundson VS (1945) Crooked neck dwarf in the domestic fowl. J Hered 36:173-176.

Atsumi S (1977) Development of neuromuscular junctions of fast and slow muscles in the chick embryo: a light and electron microscope study. J Neurocytol 6:691-709.

Barde YA (1988) What, if anything, is a neurotrophic factor? Trends Neurosci 11:343-346.

Barnard EA, Lyles LM, Pizzey JA (1982) Fibre types in chicken skeletal muscles and their changes in muscular dystrophy. J Physiol (Lond) 331:333-354.

Bennett MR, Davey DF, Marshall JJ (1983) The growth of nerves in relation to the formation of premuscle cell masses in the developing chick forelimb. J Comp Neurol 215:217-227.

Bloch-Gallego E, Huchet M, El M'Hamdi H, Xie F-K, Tanaka H, Henderson CE (1991) Survival in vitro of motoneurons identified by novel antibody-based methods is selectively enhanced by musclederived factors. Development 111:221-232.

Born DE, Rubel EW (1988) Afferent influences on brain stem auditory nuclei of the chicken. J Neurosci 8:901-919.

Bourgeois JP, Toutant M (1982) Innervation of avian latissimus dorsi muscles and axonal outgrowth pattern in the posterior latissimus dorsi motor nerve during embryonic development. J Comp Neurol 208:115.

Bournaud R (1980) Electrophysiological studies of neuromuscular transmission in muscular dysgenesis in the mouse: $m d g / m d g$. Int Soc Dev Neurosci Abstr (Strasbourg) 1:190.

Butler J, Cosmos E, Brierley J (1982) Differentiation of muscle fiber types in aneurogenic brachial muscles of the chick embryo. J Exp Zool 224:65-80.

Calof AL, Reichardt LF (1984) Motoneurons purified by cell sorting respond to two distinct activities in myotube-conditioned medium. Dev Biol 106:194-210.

Chu-Wang IW, Oppenheim RW (1978) Cell death of motoncurons in the chick embryo spinal cord. J Comp Neurol 177:33-86.

Dahm LM, Landmesser L (1988) The regulation of intramuscular nerve branching during normal development and following activity blockade. Dev Biol 130:621-644.

Davies AM (1988) The emerging generality of the neurotrophic hypothesis. Trends Neurosci 11:243-244.

Denton CJ, Lamb AH, Wilson P, Mark RF (1985) Innervation pattern of muscles of one-legged Xenopus laevis supplied by motoneurons from both sides of the spinal cord. Brain Res 349:85-94.

Dohrmann U, Edgar D, Sendtner M, Thoenen H (1986) Muscle-derived factors that support survival and promote fiber outgrowth from embryonic chick spinal motor neurons in culture. Dev Biol 118:209221.

Dohrmann U, Edgar D, Thoenen H (1987) Distinct neurotrophic factors from skeletal muscle and the central nervous system interact synergistically to support the survival of cultured embryonic spinal motor neurons. Dev Biol 124:145-157.

Forger NG, Breedlove SM (1987) Motoneuronal death during human fetal development. J Comp Neurol 264:118-122.

Fredette BJ, Landmesser LT (1991) A reevaluation of the role of 
innervation in primary and secondary myogenesis in developing chick muscle. Dev Biol 143:19-35.

Furber S, Oppenheim RW, Prevette D (1987) Naturally occurring neuron death in the ciliary ganglion of the chick embryo following removal of preganglionic input: evidence for the role of afferents in ganglion cell survival. J Neurosci 7:1816-1832.

Gluecksohn-Waelsch S (1963) Lethal genes and analysis of differentiation. Science 142:1269-1276.

Gordon T, Purves RD, Vrbova G (1977) Differentiation of electrical and contractile properties of slow and fast muscle fibres. J Physiol (Lond) 269:535-547.

Hamburger V (1963) Some aspects of the embryology of behavior. $Q$ Rev Biol 38:243-365.

Hamburger V (1966) A manual of experimental embryology. Chicago: The Universily of Chicago Press.

Hamburger V (1975) Cell death in the development of the lateral motor column of the chick embryo. J Comp Neurol 160:535-546.

Hamburger V, Hamilton $H$ (1951) A series of normal stages in the development of the chick embryo. J Morphol 88:49-92.

Hamburger V, Oppenheim RW (1982) Naturally occurring neuronal death in vertebrates. Neurosci Comment 1:39-55.

Harper S, Davies AM (1990) NGF mRNA expression in developing cutaneous epithelium related to innervation density. Development 110:515-519.

Harris AJ (1981) Embryonic growth and innervation of rat skeletal muscles. Trans R Soc Lond [Biol] 293:257-277.

Harris AJ, McCaig CD (1984) Motoneuron death and motor unit size during embryonic development of the rat. J Neurosci 4:13-24.

Henderson CE, Huchet M, Changeux JP (1981) Neurite outgrowth from embryonic chicken spinal neurons is promoted by media conditioned by muscle cells. Proc Natl Acad Sci USA 78:2625-2629.

Henderson CE, Huchet M, Changeux JP (1983) Denervation increases a neurite-promoting activity in extracts of skeletal muscle. Nature 302:609-611.

Henderson CE, Benoit P, Huchet M, Guenet JL, Changeux JP (1986) Increase of neurite-promoting activity for spinal neurons in muscles of "paralyse" mice and tenotomized rats. Dev Brain Res 25:65-70.

Hill MA, Bennett MR (1983) Cholinergic growth factor from skeletal muscle is elevated following denervation. Neurosci Lett 35:31-35.

Hill MA, Bcnnctt MR (1986) Motoneuron survival activity in extracts of denervated muscle reduced by prior stimulation of the muscle. Dev Brain Res 24:305-308.

Houenou LJ, Prevette D, Oppenheim RW (1989) Motoneuron survival in vitro following treatment with extracts from active and inactive muscle. Soc Neurosci Abstr 15:436.

Houenou LJ, Haverkamp LJ, Kunzi R, Oppenheim RW (1990a) Effects of muscle inactivity and innervation on the regulation of a putative muscle-derived neurotrophic agent: in vivo and in vitro studies. Soc Neurosci Abstr 16:170.

Houenou LJ, Pinçon-Raymond M, Garcia L, Harris AJ, Rieger F (1990b) Neuromuscular development following tetrodotoxin-induced inactivity in mouse embryos. J Neurobiol 21:1249-1261.

Hsu L, Natyzak D, Trupin GL (1982) Neurotrophic effects of skeletal muscle fractions on spinal cord differentiation. J Embryol Exp Morphol 71:33-95.

Hsu L, Natyzak D, Trupin GL (1984) Neurotrophic effects of skeletal muscle fractions on neurite development. Muscle Nerve 7:211-217.

Ishida I, Deguchi T (1983) Effect of depolarizing agents on choline acetyltransferase and acetylcholinesterase activities in primary cell cultures of spinal cord. J Neurosci 3:1818-1823.

Laing N, Prestige M (1978) Prevention of spontaneous motoneurone death in the chick embryo. J Physiol (Lond) 282:33-34.

Lamb AH (1980) Motoneuron counts in Xenopus frogs reared with one bilaterally innervated hindlimb. Nature 284:347-350.

Lamb AH, Sheard PW, Ferns MJ (1988) Meritocratic selection hypothesis in the control of motoneuron death during development. In: Developmental neurobiology of the frog. (Pollack ED, Bibb HD, eds), pp 53-76. New York: Liss.

Lance-Jones C (1982) Motoneuron cell death in the developing spinal cord of the mouse. Dev Brain Res 4:473-479.

Landmesser L (1978) The distribution of motoneurons supplying chick hind limb muscles. J Physiol (Lond) 284:371-389.

Landmesser L, Szente M (1987) Activation pattern of embryonic chick hind-limb muscles following blockade of activity and motoneuron cell death. J Physiol (Lond) 380:157-174.
Landmesser L, Dahm L, Schultz K, Rutishauser U (1988) Distinct roles for adhesion molecules during innervation of embryonic chick muscle. Dev Biol 130:645-670.

Landmesser L, Dahm L, Tang J, Rutishauser U (1990) Polysialic acid as a regulator of intramuscular nerve branching during embryonic development. Neuron 4:655-667.

Lowry OH, Rosebrough NJ, Farr AL, Randall RJ (1951) Protein measurement with folin phenol reagent. J Biol Chem 193:265-275.

Maderdrut IL, Oppenheim RW, Prevette D (1988) Enhancement of naturally occurring cell death in the sympathetic and parasympathetic ganglia of the chicken embryo following blockade of ganglionic transmission. Brain Res 444:189-194.

Martinou JC, Le Van Thai A, Cassar G, Roubinet F, Weber MJ (1989) Characterization of two factors enhancing choline acetyltransferase activity in cultures of purified rat motoneurons. J Neurosci 9:36453656.

McManaman JL, Smith RG, Appel SH (1985) Low-molecular-weight peptide stimulates cholinergic development in ventral spinal cord cultures. Dev Biol 112:248-252.

McManaman JL, Crowford FS, Stewart SS, Appel SH (1988) Purification of a skeletal muscle polypeptide which stimulates choline acetyltransferase activity in cultured spinal cord neurons. J Biol Chem 263:5890-5897.

McManaman JL, Oppenheim RW, Prevette D, Marchetti D (1990) Rescue of motoneurons from naturally occurring death by a purified skeletal muscle polypeptide: in vivo and in vitro effects of the choline acetyltransferase development factor. Neuron 4:891-898.

Nurcombe V, Hill MA, Eagleson KL, Bennett MR (1984) Motor neuron survival and neurite extension from spinal cord explants induced by factors released from denervated muscle. Brain Res 291:19-28.

O'Brien RJ, Fischbach GD (1986) Isolation of embryonic chick motoneurons and their survival in vitro. J Neurosci 6:3265-3274.

Okado N, Oppenheim RW (1984) Cell death of motoneurons in the chick embryo spinal cord. IX. The loss of motoneurons following removal of afferent inputs. J Neurosci 4:1639-1652.

O'Leary DDM, Cowan WM (1984) Survival of isthmo-optic neurons after removal of one eye. Dev Brain Res 12:293-310.

Oppenheim RW (1982) The neuroembryological study of behavior: progress, problems, perspectives. In: Current topics in developmental biology, Vol 17, neural development (Hunt RK, ed), pp 257-309. New York: Academic.

Oppenheim RW (1984) Cell death of motoneurons in the chick embryo spinal cord. VIII. Motoneurons prevented from dying in the embryo persist after hatching. Dev Biol 101:35-39.

Oppenheim RW (1986) The absence of significant postnatal motoneuron death in the brachial and lumbar spinal cord of the rat. $J$ Comp Neurol 246:281-286.

Oppenheim RW (1987) Muscle activity and motor neuron death in the spinal cord of the chick embryo. Ciba Found Symp 126:96-112.

Oppenheim RW (1989) The neurotrophic theory and naturally occurring motoneuron death. Trends Neurosci 12:252-255.

Oppenheim RW, Chu-Wang IW (1983) Aspects of naturally-occurring motoneuron death in the chick spinal cord during embryonic development. In: Somatic and autonomic nerve-muscle interactions (Burnstock G, Vrbova G, eds), pp 57-107. Amsterdam: Elsevier.

Oppenheim RW, Prevette D (1986) Neuromuscular development in the crooked neck dwarf mutant (cn/cn) chick embryo. Soc Neurosci Abstr 12:983.

Oppenheim RW, Houenou L, Pinçon-Raymond M, Powell JA, Rieger F, Standish LJ (1986) The development of motoneurons in the embryonic spinal cord of the mouse mutant, muscular dysgenesis ( $m d g / m d g$ ): survival, morphology and biochemical differentiation. Dev Biol 114:426-436.

Oppenheim RW, Haverkamp LJ, Prevette D, McManaman JL, Appel SH (1988) Reduction of naturally occurring motoneuron death in the chick embryo in vivo by a target-derived neurotrophic factor. Science 240:919-922.

Oppenheim RW, Bursztajn S, Prevette D (1989) Cell death of motoneurons in the chick embryo spinal cord. XI. Acetylcholine receptors and synaptogenesis in skeletal muscle following the reduction of motoneuron death by neuromuscular blockade. Development 107: $331-341$.

Pai AI (1965) Developmental genetics of a lethal mutation $(m d g)$ in the mouse. Dev Biol 11:82-109.

Pasic TR, Rubel EW (1989) Rapid changes in cochlear nucleus size 
following activity blockade of auditory nerve electrical activity in gerbils. J Comp Neurol 283:474-480.

Pestronk A, Drachman D (1978) Motor nerve sprouting and acetylcholine receptors. Science 199:1223-1225.

Phillips WD, Bennett MR (1984) Differentiation of fiber types in wing muscles during embryonic development: effect of neural tube removal. Dev Biol 106:457-468.

Pittman R, Oppenheim RW (1978) Neuromuscular blockade increases motoneuron survival during cell death in the chick embryo. Nature 271:364-366.

Pittman R, Oppenheim RW (1979) Cell death of motoneurons in the chick embryo spinal cord. IV. Evidence that a functional neuromuscular interaction is involved in the regulation of naturally occurring cell death and the stabilization of synapses. J Comp Neurol 187:425446.

Rieger F, Bournaud R, Pinçon-Raymond M, Dreyfus P, Blondet B, Tran LH (1980) Neurobiological defects of muscle and nerve in murine muscular dysgenesis ( $m d g / m d g$ ). Soc Neurosci Abstr 10:744

Rohrer H, Heumann R, Thoenen H (1988) The synthesis of nerve growth factor (NGF) in developing skin is independent of innervation. Dev Biol 128:240-244.
Rosemberg LE (1947) Histological studies of muscle from crooked neck dwarf fowl. Anat Res 97:277-282.

Ross JJ, Duxson MJ, Harris AJ (1987a) Formation of primary and secondary myotubes in rat lumbrical muscles. Development 100:383394.

Ross JJ, Duxson MJ, Harris AJ (1987b) Neural determination of muscle fibre numbers in embryonic rat lumbrical muscles. Development 100:395-409.

Srihari T, Vrbova G (1978) The role of muscle activity in the differentiation of neuromuscular junctions in slow and fast chick muscles. J Neurocytol 7:529-540.

Tanaka H (1987) Chronic application of curare does not increase the level of motoneuron survival-promoting activity in limb muscle extracts during the naturally occurring motoneuron cell death period. Dev Biol 124:347-357.

Wich RA, Allenspach AL (1978) Histological study of muscular hypoplasia in the crooked neck dwarf mutant $(\mathrm{cn} / \mathrm{cn})$ chick embryo. J Morphol 158:21-30.

Wright L (1981) Cell survival in chick embryo ciliary ganglion is reduced by chronic ganglionic blockade. Dev Brain Res 1:283-286. 